\title{
Experimental and numerical investigations regarding laser drop on demand jetting of $\mathrm{Cu}$ alloys
}

\author{
Stefan Stein ${ }^{1,3}$ - Michael Dobler ${ }^{2,3} \cdot$ Tim Radel $^{4} \cdot$ Markus Strau $^{2,3}$. \\ Hannes Breitschwerdt ${ }^{2}$. Florian Hugger ${ }^{1}$ Stephan Roth $^{1,3} \cdot$ Michael Schmidt $^{1,2,3}$
}

Received: 30 November 2016 / Accepted: 27 April 2017 / Published online: 5 May 2017

(C) The Author(s) 2017. This article is an open access publication

\begin{abstract}
Active noise reduction, structural health monitoring and energy harvesting are possible applications of active structure components. An integration of piezoceramic modules into casted Al-structures can be defined as a long term goal to achieve high functional integration and thus to address lightweight construction. Since the liquidus temperature of standard electronic solder is not sufficient to withstand the thermal loads during $\mathrm{Al}$ die casting processes, a suitable wire bonding process is an enabling technology to generate active $\mathrm{Al}$ structures. In the scope of this work, a laser based drop on demand joining process is introduced. The process consists of four main steps. First a spherical CuSn 12 braze preform of $600 \mu \mathrm{m}$ diameter with a liquidus temperature of $1233 \mathrm{~K}$ is inserted into a ceramic capillary and being molten by a laser pulse. The droplet is subsequently ejected by gas overpressure and impinges on the joining area, consisting of the electrode structure of the piezo element and the $\mathrm{Cu}$ wire, where it forms a firm joint of the $\mathrm{Cu}$ wire and the electrode structure. In order to evaluate time-temperature profiles of the capillary during melting and detachment of the braze preform a simulation
\end{abstract}

Stefan Stein

s.stein@blz.org

1 Bayerisches Laserzentrum Erlangen $\mathrm{GmbH}$, Konrad-Zuse-Straße 2-6, 91052 Erlangen, Germany

2 Institute of Photonic Technologies (LPT), Friedrich-Alexa nder-Universität Erlangen-Nürnberg, Konrad-Zuse-Str. 3-5, 91052 Erlangen, Germany

3 Erlangen Graduate School in Advanced Optical Technologies (SAOT), Friedrich-Alexander-Universität Erlangen-Nürnberg, Paul-Gordan-Str. 6, 91052 Erlangen, Germany

4 BIAS Bremer Institut fuer angewandte Strahltechnik GmbH, Klagenfurter Str. 2, 28359 Bremen, Germany model was set up, indicating heating and cooling rates of $22,100 \mathrm{~K} / \mathrm{s}$. Further, the impact of the capillary geometry on the velocity fields of a passing medium was evaluated. By changing the capillary geometry, the gas flow velocity could be reduced by about $10 \%$ according to the simulation model, which resulted in a reduction of droplet height deviation of $7.5 \%$ and a reduction of the droplet diameter deviation of $32.2 \%$ in the experiment.

Keywords Laser droplet brazing - Drop on demand . Electrical joining · Computational fluid dynamics · Process simulation $\cdot$ Laser bonding

\section{Introduction and motivation}

Automotive and aerospace industry are facing increasingly stringent laws regarding environmental protection. In order to decrease energy consumption and thus pollutant emission, a reduction of component weight is one approach to meet legislative requirements. One method to achieve this goal is the substitution of redundant parts by integrated structural components, which meet several requirements in a single structure. So called adaptronic devices can be manufactured by integrating piezo actuators into structural parts generated e.g. by aluminum die casting and thus can provide functionalities like structural health monitoring or active vibration damping [1]. These composite assemblies with sensor and/or actuator functionalities thus became focus of interest of different engineering fields in recent years [2-4]. Since the electrical joints of the actuator modules need to withstand significant thermal loads of $>600^{\circ} \mathrm{C}$, particularly during the casting process $[5,6]$, a novel laser assisted bonding process has been developed, and is referred to as laser drop on demand joining. The 
process is described in [7-9] and was proven suitable for generating electrical joints of $20 \mu \mathrm{m}$ Ag-electrode structures with 100 up to $200 \mu \mathrm{m} \mathrm{Cu}$-wires [10]. The process can be divided into four phases. First, a braze preform is inserted into a capillary, where it is irradiated by a laser pulse. The laser pulse thoroughly melts the preform which is subsequently ejected from the capillary by nitrogen overpressure. After a flight phase, the molten droplet wets the electrode structure of the piezo actuator and the $\mathrm{Cu}$-wire, resulting in a firm joint (Fig. 1).

However, since the process is still under development, several of the occurring effects are not yet fully understood. For instance, in preliminary investigations large deviations of droplet height and diameter were found, which were traced back to the impulse of gas molecules on the molten droplet during its solidification, which results in arbitrary joint shapes after solidification. Thus, the goal of the investigations was to evaluate, whether the capillary shape can influence the final joint geometry by modifying the distribution of the gas flow velocity field at the capillary orifice respectively in the joining area. Another important aspect is the wetting behavior of the used braze alloy in liquid state with the solid capillary material. Consequently the surface energies between molten $\mathrm{CuSn} 12$ braze, $\mathrm{Al}_{2} \mathrm{O}_{3}$ ceramic and surrounding gas were measured using the sessile drop method. The measured wetting angles were implemented in a numerical model, in order to assess wetting behavior and fluid dynamics during irradiation and detachment of the braze material from the capillary.

\section{Experimental setup, simulation model and boundary conditions}

In the experiment, a fiber laser with a wavelength of $1070 \mathrm{~nm}$, a maximum optical output power of $200 \mathrm{~W}$ and a collimated beam diameter of $6.9 \mathrm{~mm}$ is used to irradiate and melt the braze preform. It is focused by a lens of focal length $f=50 \mathrm{~mm}$ which results in a theoretical spot diameter of $10.9 \mu \mathrm{m}$. Yet, in order to avoid a perforation of the braze preform, the intensity distribution has been adjusted to match the braze preform diameter by working with a focus offset. Thus in the simulation model the beam diameter was adapted to the diameter of the braze preform of $600 \mu \mathrm{m}$. The absorption of the laser radiation on the preform surface results in its heating which, by means of convective and conductive heat transfer, leads to the formation of a temperature field and complete melting of the braze preform. Further, since the force of surface tension of the molten braze volume exceeds the gravity force [11], nitrogen overpressure of minimum 80 mbar needs to be applied in the experiment in order to ensure detachment of the droplet from the capillary, which is also implemented in the simulation model. For a detailed description of the experimental setup see [10].

\subsection{Model geometry and meshing for evaluation of thermal cycle during joining}

In order to evaluate the thermal input into the capillary during laser irradiation, energy absorption and heating of the braze preform, and to quantify the influence of the capillary shape on the gas flow velocities at the capillary orifice as well as in the joining area, a fluid dynamic simulation was done using a multi-physical simulation approach. The model used is based on a model which has already been successfully applied to several laser based joining processes $[12,13]$. The numerical problem is solved by applying finite volume methods and takes the underlying physics of beam/matter interaction, wetting phenomena and heat conduction as well as fluid dynamics into account. It was implemented using the open source computational fluid dynamics (CFD) software package OpenFoam (Open Field Operation And Manipulation, ${ }^{\circ}$ OpenCFD Limited). The numerical model consists of 190,000 hexaeder elements. Meshing has been carried out using the software ANSYS ICEM. The final model consists of five discrete components (see Fig. 2).
A. The capillary made of the technical ceramic $\mathrm{Al}_{2} \mathrm{O}_{3}$
B. The braze preform made of $\mathrm{CuSn} 12$
C. The copper wire serves as the conductor of the current $(\varnothing=100 \mu \mathrm{m})$

Fig. 1 Schematic of laser drop on demand joining process

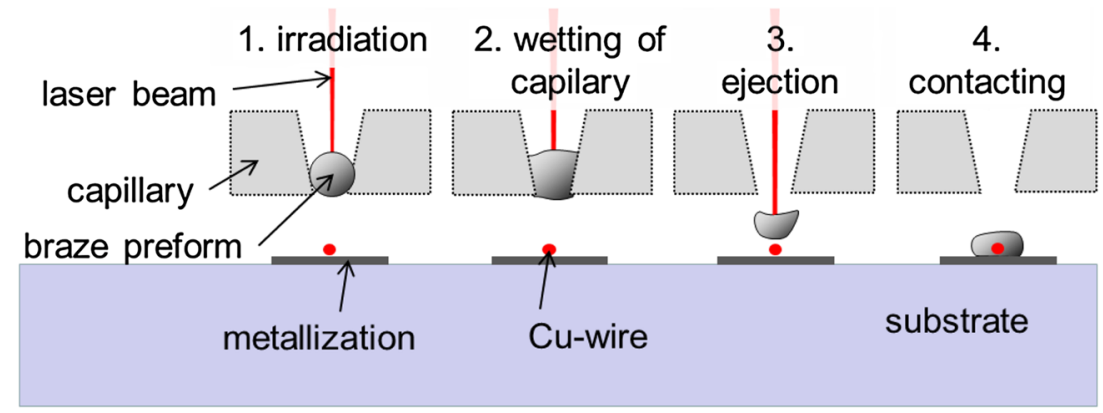



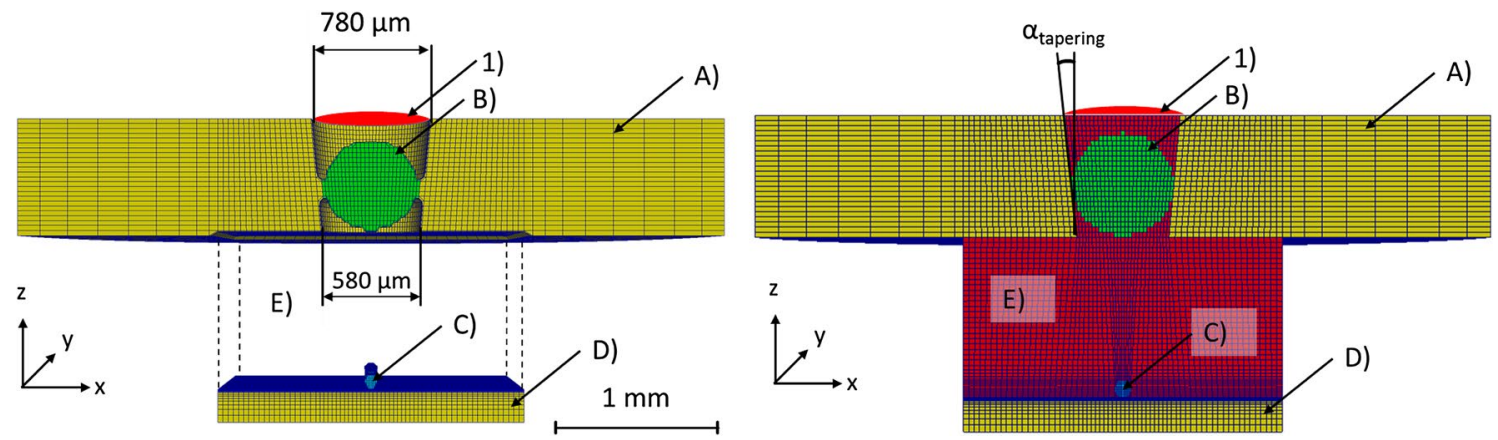

Fig. 2 Meshed model of capillary $(A)$, braze preform $(B)$, substrate with metallisation $(D)$ and Cu conductor $(C)$ at time step 0 without air body (left) and with air body (right), gas pressure is applied at surface 1

D. The ceramic substrate consisting of a low temperature cofired ceramic (LTCC) and the Ag-metallization layer, which serves as solder pad respectively electrode structure of the piezo element

E. The air body connecting the described discrete components is visualized red in Fig. 2 (right).

Figure 2 shows the meshed model at time step 0 . The tapering angle of the capillary is $8.13^{\circ}$. The boundary conditions are applied at the boundaries enveloping the volumes of the discrete components described above.

The material properties used in the simulation are shown in Table 1.

For the ceramic with the Ag electrode structure, located at the bottom of the model ( $\mathrm{D}$ in Fig. 2), phase transportation is not permitted, since the ceramic is not being molten during droplet detachment and impact. Initially, the pressure and velocity values of the discrete phases are set zero, resembling the initial state of the experiment. As the experiment is carried out at room temperature, the initial global temperature of the model is set to $293 \mathrm{~K}$. The air body, connecting capillary, braze preform, metallization and $\mathrm{Cu}$ conductor, disposes of two boundary conditions: In $\mathrm{x}$ - and $\mathrm{y}$-direction the boundary is defined to permit gas and temperature exchange through the interface boundary. In z-direction, at the top of the model (surface 1 in Fig. 2), a defined gas overpressure is applied, which resembles the overpressure building up inside the machining head during the joining process. In addition, laser intensity is applied at surface 1 and is being projected onto the braze preform. The capillary is modeled from a round $\mathrm{Al}_{2} \mathrm{O}_{3}$ disc with a conic cavity. The lower diameter is $580 \mu \mathrm{m}$ and the upper diameter $780 \mu \mathrm{m}$, which, due to the convex shape, will hold the spherical braze preform with a diameter of $600 \mu \mathrm{m}$ in place. Since absorption defines the energy input into the braze preform, to accurately model temperature input and distribution on the curved surface, Fresnel absorption is considered by applying the Fresnel equation to calculate angle dependent energy deposition. Absorbed laser radiation is implemented as a heat source, which leads to an increasing surface temperature of the braze preform and finally results in its complete melting.

To model the melting process of the preform, the heat equation with convective and conductive heat transfer is

Table 1 Material properties used in the simulation for air, capillary material and braze material

\begin{tabular}{|c|c|c|c|}
\hline Density $\rho$ & Air & $\mathrm{Al}_{2} \mathrm{O}_{3}$ (capillary) & CuSn12 (braze preform) \\
\hline Heat capacity $c_{p}$ & $1.188 \mathrm{~kg} \mathrm{~m}^{-2} \mathrm{~K}^{-1}$ & $831 \mathrm{~kg} \mathrm{~m}^{-2} \mathrm{~K}^{-1}[14]$ & $\begin{array}{l}367 \mathrm{~kg} \mathrm{~m}^{-2} \mathrm{~K}^{-1} \text { by the rule of mix- } \\
\text { tures according to [15] }\end{array}$ \\
\hline Heat conduction $\lambda$ & $0.026 \mathrm{~W}(\mathrm{~m} \mathrm{~K})^{-1}$ & $34.7 \mathrm{~W}(\mathrm{~m} \mathrm{~K})^{-1}[16]$ & $51 \mathrm{~W}(\mathrm{~m} \mathrm{~K})^{-1}[17]$ \\
\hline Surface tension $\sigma$ & - & $760 \mathrm{mN} \mathrm{m}^{-1 \mathrm{a}}$ & $1825 \mathrm{mN} \mathrm{m}^{-1}[18]$ \\
\hline Dynamic viscosity $\gamma d y n$ & $18.24 \times 10^{-6} \mathrm{~Pa} \mathrm{~s}$ & - & - \\
\hline Kinematic viscosity $\gamma_{\text {Kin }}$ & $1.48 \times 10^{-3} \mathrm{~m}^{2} \mathrm{~s}^{-1}$ & - & $5.352 \times 10^{-7} \mathrm{~m}^{2} \mathrm{~s}^{-1}[19]$, value for $\mathrm{Cu}$ \\
\hline Melting temperature $T_{\text {melt }}$ & - & $2223 \mathrm{~K}$ & $1,062-1,233 \mathrm{~K}[17]$ \\
\hline Enthalpy of fusion $H_{m e l t}$ & - & $400,000 \mathrm{~m}^{2} \mathrm{~s}^{-1 b}$ & $91,300 \mathrm{~m}^{2} \mathrm{~s}^{-1}[20]$ \\
\hline
\end{tabular}

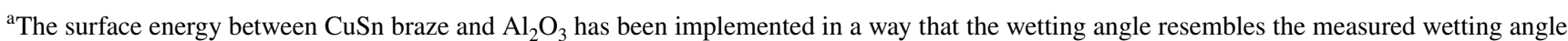
of $\mathrm{Al}_{2} \mathrm{O}_{3}$ with molten copper

${ }^{\mathrm{b}}$ The enthalpy of fusion was set to a high value, since the capillary material is not being molten during the process 
solved, taking the enthalpy of fusion into account, which plays a crucial role in the energy balance during melting and solidification of brazing processes [12]. For each volume element, the temperature $T$ is thus determined by applying the heat transfer equation (Eq. 1) in which $\rho$ denotes the density, $\vec{u}$ the fluid velocity vector, $L$ refers to the latent heat, $T$ to the absolute temperature and $t$ to the relative time:

$Q=\frac{\partial(\rho H)}{\partial t}+\nabla \cdot(\rho \vec{u} H)-\nabla \cdot(\lambda \nabla T)$

Thereby $\mathrm{H}$ is the enthalpy defined as the heat capacity $c_{p}$ multiplied by the absolute temperature $T$ plus the latent heat $L$ :

$H=c_{p} T+L$

The source term $Q$ in Eq. 1 corresponds to the absorbed energy available for heating the braze preform. The heat transfer equation is subsequently solved iteratively for every time step. Since the goal of the simulation is to accurately simulate the process behavior particularly regarding fluid dynamics of the melt during heating and detachment from the capillary, its wetting behavior with the capillary material have to be considered in order to obtain realistic results. Therefore, CuSn12 braze material, capillary material and air volume were modeled as individual incompressible fluid phases. To enable an analytic process description of a multi-phase system, a coupled system of differential equations needs to be solved. First, conservation of mass is ensured by implementing the continuity equation (Eq. 3):

$\frac{\partial \rho}{\partial t}+\nabla \cdot(\rho \vec{u})=0$

Furthermore, to account for the different phases, the phase transport equation is taken into consideration:

$\frac{\partial \alpha}{\partial t}+\nabla \cdot(\alpha \vec{u})=0$

whereby $\alpha$ is the phase indicator function which specifies the volume fraction occupied by each phase. The Navier-Stokes equation which corresponds to momentum conservation is given by:

$\rho \frac{\partial \vec{u}}{\partial t}+\rho \vec{u} \times \nabla \vec{u}=-\rho \nabla p+\eta \Delta \vec{u}$

and is solved, using the PISO scheme [21]. To determine the coordinates of the free surface between liquid braze material and surrounding air, respectively capillary, the volume of fluid (VOF) approach according to [22] is applied. This approach was chosen, in order to obtain a good description of the relevant wetting phenomena which is needed for an accurate simulation of the droplet detachment from the capillary. A surface tension model [23] was therefore adapted to enable the calculation of surface tension effects for multiple phases and includes both radial and tangential forces on the fluids.

\subsection{Wetting behavior of $\mathrm{Al}_{2} \mathrm{O}_{3}$ capillary and molten CuSn12 braze}

Since understanding the wetting behavior of the used capillary material is crucial for process modelling, the surface energies occurring at the solid/liquid/gas phase between molten $\mathrm{CuSn} 12$ braze, $\mathrm{Al}_{2} \mathrm{O}_{3}$ ceramic and surrounding gas were measured using the sessile drop method (Fig. 3).

To generate liquid CuSn12 droplets on $\mathrm{Al}_{2} \mathrm{O}_{3}$ substrates, a process chamber with inert gas atmosphere as described in [24] was used, to resemble similar conditions as in the described droplet joining process. During the wetting experiment, a wire feeder imposes the CuSn 12 wire into the process chamber, enabling the irradiation of the wire tip via a window with a laser pulse of $2 \mathrm{~kW}$ laser power and $2 \mathrm{~s}$ pulse duration. The wire tip gets molten and droplet detachment is enforced by abrupt retracting of the wire. The droplet thus wets the ceramic substrate placed below the wire after a short flight phase. Due to the low thermal conductivity of the ceramic of $34.7 \mathrm{~W} /$ $\mathrm{mK}$ [16] the droplet cools below solidus temperature after the stationary wetting angle is exhibited. The laser drop on demand joining setup described in [10] could not be used to determine the wetting angle, since the impulse of the process gas jet influences the droplet shape during its cooling, before a stationary wetting angle is exhibited. The wetting experiment is monitored by means of highspeed imaging. Figure 4 shows a schematic of the experimental setup and the stationary wetting angle exhibited at the interface of molten $\mathrm{CuSn} 12$ and $\mathrm{Al}_{2} \mathrm{O}_{3}$. The value of

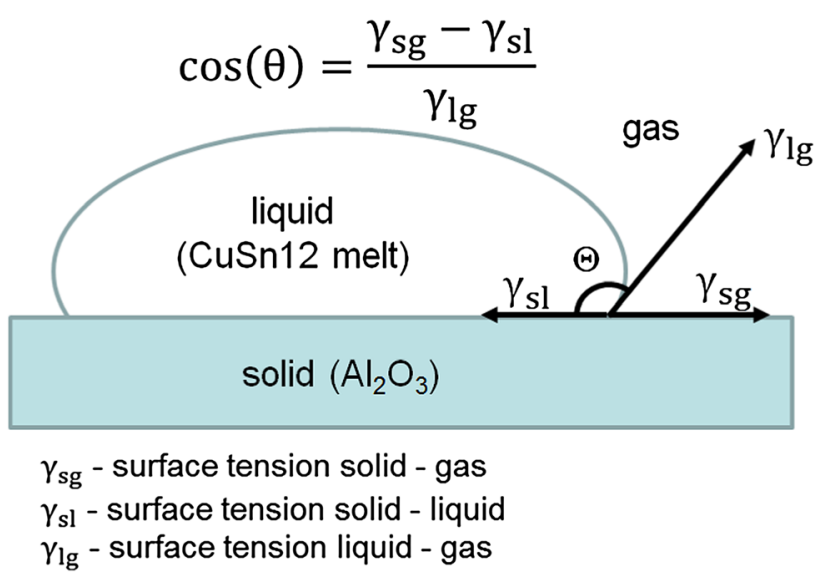

Fig. 3 Determining the surface tension by sessile drop method 
Fig. 4 Experimental setup for determination of wetting angle $\left(\lambda_{\text {Laser }}=1030 \mathrm{~nm}\right.$; $\mathrm{P}_{\text {Laser }}=2 \mathrm{~kW}$; $\mathrm{v}_{\text {Wire }}=1 \mathrm{~m} / \mathrm{min}$; $\mathrm{t}_{\text {Pulse }}=2 \mathrm{~s}$ )

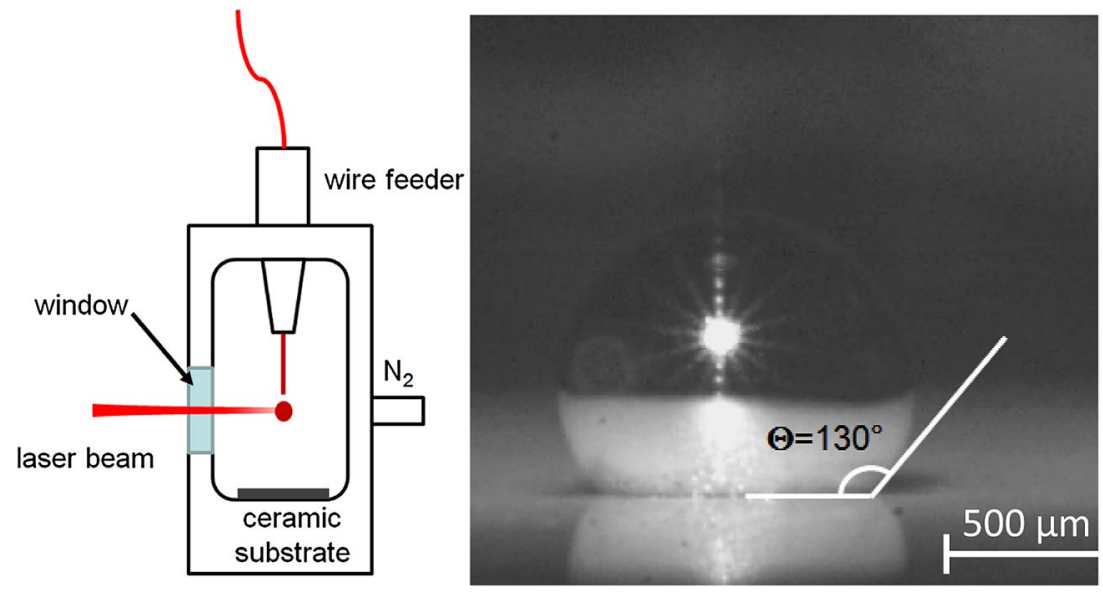

the stationary wetting angle $\Theta$ was measured to be $130^{\circ}$ in liquid, stationary state. Subsequently the wetting angle was implemented in the simulation model.

\subsection{Influence of capillary shape on gas flow velocities}

In preceding experiments, significant deviations of joint shapes have been observed. This was mainly accounted for, by the impulse induced by the processing gas onto the molten droplet while wetting the electrode structure, which results in droplet height and diameter variations after solidification of the melt. Thus the gas jet modifies the droplet geometry arbitrarily during the solidification of the melt. Altering the shape of a capillary influences the fluid dynamic behavior of a passing medium significantly and was studied extensively in recent years [25, 26]. Thus it can be assumed, that modifying the capillary geometry would help to reduce gas flow impact on the molten braze material after droplet detachment and during wetting phase, which can be obtained by using a diffuser type capillary shape, which broadens and homogenizes the gas flow velocity field at the capillary orifice. Therefore, a capillary was designed, which resembles a diffuser in shape, to stabilize passing media by slowing the velocity of the process gas at the capillary orifice, resulting in a decreased impulse of gas molecules on the molten droplet in the joining area.
To evaluate the influence of the capillary geometry on gas flow velocities, a three dimensional simulation model consisting of 90,500 hexaeder elements was used. Figure 5 shows the conic capillary used for joining (geometry 1) with an upper diameter of $780 \mu \mathrm{m}$ and an orifice diameter of $580 \mu \mathrm{m}$ as well as a diffusor type capillary, consisting of a conic shaped cavity with an upper diameter of $780 \mu \mathrm{m}$ and a waist diameter of $580 \mu \mathrm{m}$ in the center of the ceramic plate. This convex shape is necessary to hold the braze preform in place. At the bottom of the capillary, a radius of the curve of $1.12 \mathrm{~mm}$ was defined, to broaden the orifice and to obtain a diffusing effect on the passing process gas (Fig. 5).

The two capillary shapes were machined by laser ablation using a picosecond laser for structuring a cavity into an $\mathrm{Al}_{2} \mathrm{O}_{3}$ disc. To generate the desired geometries, an ablation strategy described in [27] was used, which enables the generation of cavities of defined dimensions by laser ablation. Geometry two was generated in two steps. First the upper part of the cavity was generated, subsequently the capillary was rotated $180^{\circ}$ followed by another ablation process with modified parameters to obtain the desired geometry ( 2 in Fig. 5). The surface roughness inside the cavity of the capillary after laser ablation was measured, using a laser scanning microscope. The values for $\mathrm{Rz}$ respectively $\mathrm{Ra}$ were found to be $0.89 \pm 0.16 \mu \mathrm{m}(\mathrm{n}=5)$, respectively $0.19 \pm 0.03 \mu \mathrm{m}(\mathrm{n}=5)$, which is small in comparison with

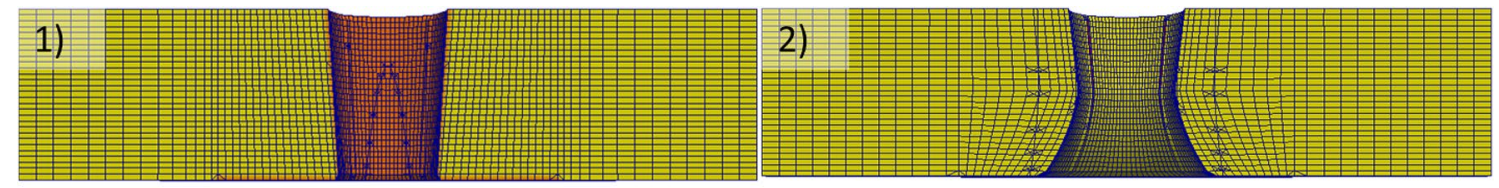

$1 \mathrm{~mm}$

Fig. 5 Meshed models of conic capillary (geometry 1) and diffuser type capillary (geometry 2) 
the preform diameter. Nevertheless microscopic capillary roughness could result in turbulent gas flow at the interface between capillary and passing medium, which is not taken into consideration in the numeric model.

\section{Results and discussion}

\subsection{Time-temperature cycle of the capillary during joining}

In earlier works, significant heating and cooling rates of the capillary during irradiation and droplet detachment were found to be the main reason for capillary failure [7]. Since it is not possible to measure the time temperature evolution inside the capillary directly, a numerical approach is used to obtain space- and time-resolved quantities regarding the thermal load of the capillary during one joining cycle. The described numerical model enables the evaluation of thermal input into the capillary by taking the underlying physical effects during irradiation, absorption, melting, wetting and droplet detachment into account. Thus the numerical model presents the only method to understand process dynamics inside the capillary. Figure 6 depicts the time-temperature evolution for four discrete points inside the conic capillary (geometry 1) during a melting cycle as numerically calculated with the simulation model.

The result shows significant thermal input in the capillary due to heat conduction from the molten braze preform during its melting and detachment process, as well as due to absorption of laser radiation in the cavity of the capillary. According to the simulation model (see Fig. 6), droplet detachment occurs shortly after $50 \mathrm{~ms}$. The heating rate at points 4 and 1 is $22,100 \mathrm{~K} / \mathrm{s}$. In the bulk material (points 2 and 3) the temperatures rise to 438 respectively $413{ }^{\circ} \mathrm{C}$, indicating heating rates of about $8700 \mathrm{~K} / \mathrm{s}$. In comparison with former results obtained by FEM simulation [7] the current results seem to be more realistic since laser irradiation, wetting behavior of $\mathrm{Al}_{2} \mathrm{O}_{3}$ and braze material as well as Fresnel absorption is taken into consideration in the described model. The findings indicate no transgression of the melting temperature of $\mathrm{Al}_{2} \mathrm{O}_{3}$ of $2323 \mathrm{~K}$ [28] during one joining cycle, which was also confirmed in the experiments. A low pressure of 120 mbar was chosen for this rather complex model, since higher pressures result in higher gas velocities, which results in a larger number of time steps necessary to be computed during the simulation which significantly increases simulation times.

To validate the simulation with the experiment, the time period from starting irradiation till droplet detachment was measured by using a photodiode, which detects scattered laser radiation after droplet detachment. The experimental results were compared with the numerical results and was found to be $50 \mathrm{~ms}$ in the simulation and $37.5 \mathrm{~ms}$ in the experiment, resembling a deviation of $33 \%$. Considering the complexity of the process, the numerical results show good conformity with the experiment. The deviation may be explained by the fact that multiple reflections are not taken into consideration in the numerical model, which results in reduced energy deposition in the numeric model in comparison to the experiment. Furthermore, the droplet velocities during the flight phase have been measured experimentally by means of high-speed imaging. The droplet velocity according to the numerical model was found to be $1.6 \mathrm{~m} / \mathrm{s}$ whereas the mean droplet velocity in the experiment was $1.9 \mathrm{~m} / \mathrm{s}(\mathrm{n}=5)$ and thus is $13 \%$ higher, which can be explained by the measurement error in the experiment. In addition, the micro roughness of the capillary in
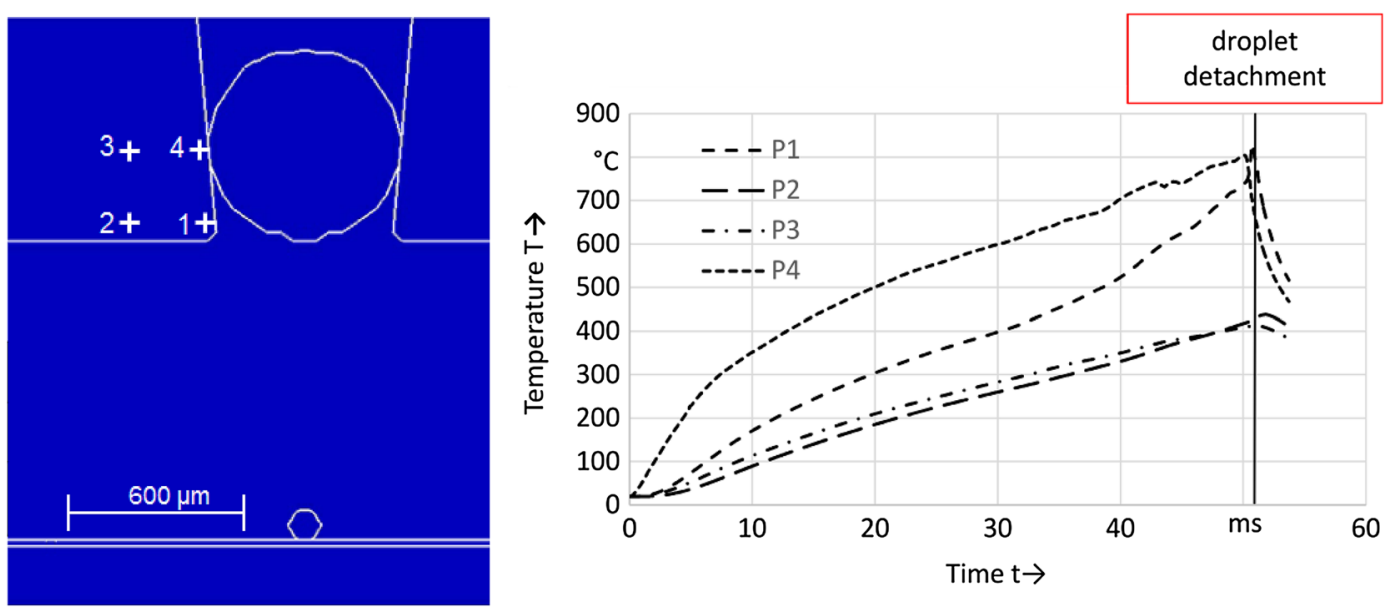

Fig. 6 Simulation of time-temperature cycle at four discrete points inside the capillary over time during a melting cycle $\left(\mathrm{P}_{\text {Laser }}=150 \mathrm{~W}\right.$, mean intensity $=5.236 \times 10^{9} \mathrm{~W} / \mathrm{m}^{2}, \mathrm{p}_{\mathrm{Nitrogen}}=120 \mathrm{mbar}$, capillary material: $\mathrm{Al}_{2} \mathrm{O}_{3}$, braze material: $\mathrm{CuSn} 12$ ) 
combination with the high surface tension and poor wetting behavior of melt and capillary will decrease the interface area between melt and capillary, which can result in higher droplet velocities. Since the surface tension is the sole force preventing the droplet from detaching, it can be concluded, that the numerical model incorporating the measured stationary wetting angle resembles the experiment fairly well.

\subsection{Influence of capillary geometry on the gas flow velocity}

In order to understand, how capillary geometry influences gas flow velocities at the capillary orifice and at the joining

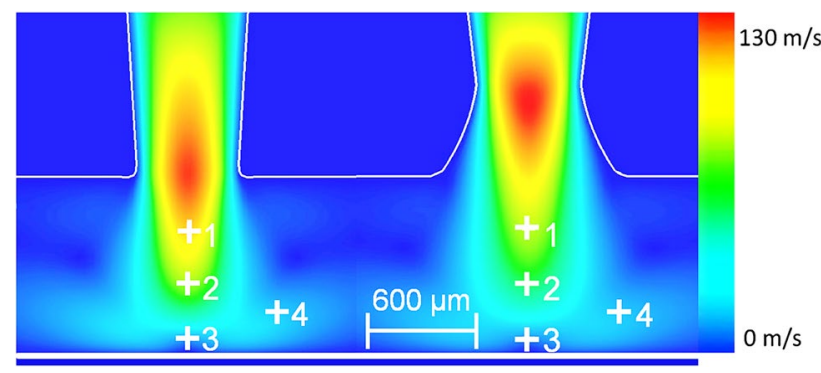

Fig. 7 Stationary gas velocity fields for conic capillary (geometry 1, left) and diffuser type capillary (geometry 2, right) after applying an overpressure of $125 \mathrm{mbar}$
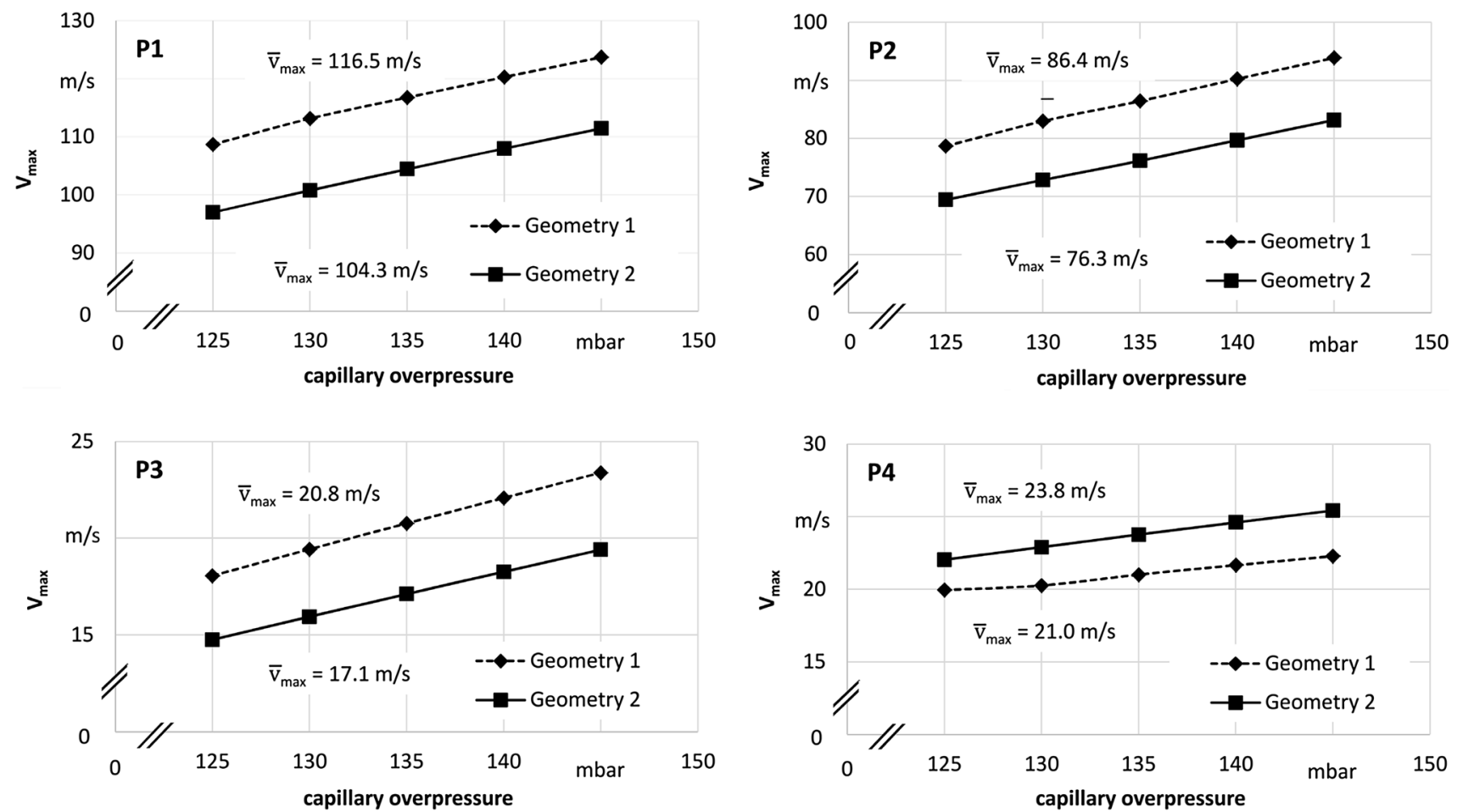

area, a second simulation model was set up, enabling direct comparison of a diffuser type capillary, with a conic capillary. Figure 7 shows the numerically acquired gas velocity fields after stationary state is reached for the conic capillary (geometry 1, left) and diffuser type capillary (geometry 2, right) after applying an overpressure of 125 mbar, which represents the standard process pressure at which good joint results can be acquired in the experiment.

The diffuser type capillary exhibits lower gas velocities in the area below the capillary than the conic shaped capillary. However, in order to give a quantitative statement regarding the reduction of gas flow velocities, four discrete points highlighted in Fig. 7 have been evaluated. The results of the particular points for various applied overpressures are shown in Fig. 8.

According to the numerical data, it can be concluded, in a reduced gas velocity in the joining area. By modifying the capillary geometry, according to the numerical model, the averaged gas flow velocity for points 1 , 2 and 3 can be reduced by 10.4, 11.8 and $17.57 \%$. For point 4 , the velocity even increases by $13.3 \%$, which can be attributed to the diffusing effect of capillary geometry 2 , which results in a more uniform distribution of the gas flow velocity fields in the joining area and thus is believed to result in a more homogeneous droplet geometry. Further, by increasing the applied overpressure, the

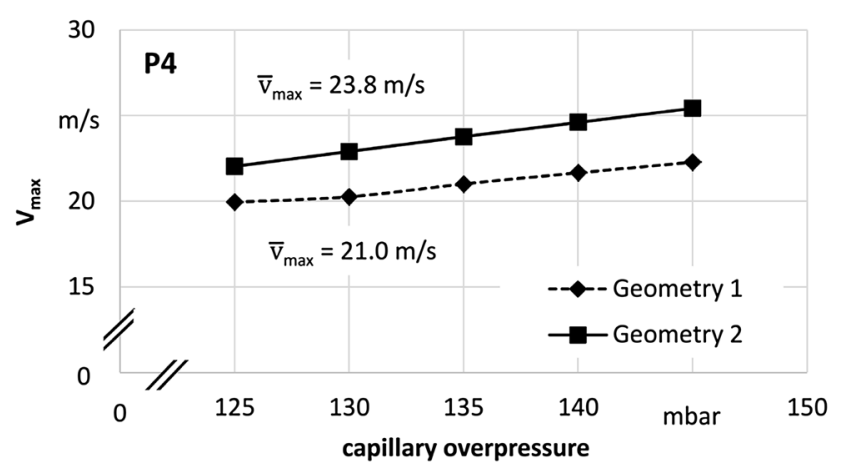
that a modification of the capillary geometry results

Fig. 8 Influence of overpressure and capillary geometry on the gas flow velocities at points 1, 2, 3 and 4 highlighted in Fig. 7 
velocities increase linearly. With decreasing distance from the substrate surface, the flow velocities increase, since the substrate acts as a barrier for the gas molecules. It is assumed that the impulse of gas molecules on the droplet during its solidification results in joint geometry deviations, which will be permanent after the temperature of the braze falls below its solidus temperature. In order to experimentally assess the influence of the overpressure and capillary geometry on the droplet geometry after its solidification, droplets are generated using both capillary types, varying the inert gas overpressure inside the machining head. Height and diameter of the droplets are measured after solidification using a laser scanning microscope, to obtain three-dimensional data of droplet topology. The experimental results are shown in Figs. 9 and 10 .

The average droplet diameter for after solidification over all pressures was reduced from $1097.6 \mu \mathrm{m}$ for capillary geometry 1 to $887.2 \mu \mathrm{m}$ for capillary geometry 2 which resembles a reduction of $19.2 \%$. The mean standard deviation of the droplet diameter over all pressures was reduced from $166 \mu \mathrm{m}$ for capillary geometry 1 to $112.6 \mu \mathrm{m}$ respectively $32.2 \%$ for capillary geometry 2 . Thus geometry 2 provides more uniform droplet shapes than the standard conic capillary, as predicted by the numerical model, which can be accounted to the homogenized gas flow velocity field generated by the diffuser type capillary. The same method was applied to evaluate the maximum droplet height (Fig. 10).

The results show a reduction of the mean droplet height after solidification from $342.9 \mu \mathrm{m}$ for the conic capillary (geometry 1) to $310.6 \mu \mathrm{m}$ for the diffuser type capillary (geometry 2 ) which represents reduction of $9.5 \%$. The standard deviation of the droplet height was reduced from $59 \mu \mathrm{m}$ for capillary geometry 1 to $54.6 \mu \mathrm{m}$ or representing a reduction of $7.5 \%$. Thus also regarding droplet height the diffuser type capillary shows higher reproducibility in comparison with the conic shaped capillary. Further, the gas overpressure seems not to be the determinant factor influencing the droplet height, since the average droplet height is almost independent of the gas overpressure. It can therefore be stated, that the impact of the capillary geometry on the droplet diameter was more significant than on the maximum droplet height (see Fig. 10). Further, regarding both aspects, the diffuser type capillary is to be favored regarding the reproducibility of the process results.

\section{Summary and conclusions}

Wire bonding by drop on demand jetting of $\mathrm{Cu}$ based braze material is a novel method of joining e.g. wires with electrode structures e.g. of piezo actuators. Since the process is still under development, the effects of inert gas overpressure and capillary shape on the droplet geometry were
Fig. 9 Influence of capillary overpressure on droplet diameter in congealed state for different capillary geometries $\left(\mathrm{P}_{\text {Laser }}=140 \mathrm{~W}\right.$, working distance $=1 \mathrm{~mm}, \mathrm{~N}=5$ )

Fig. 10 Influence of capillary overpressure on droplet height in congealed state for different capillary geometries $\left(\mathrm{P}_{\text {Laser }}=140 \mathrm{~W}\right.$, working distance $=1 \mathrm{~mm}, \mathrm{~N}=5$ )
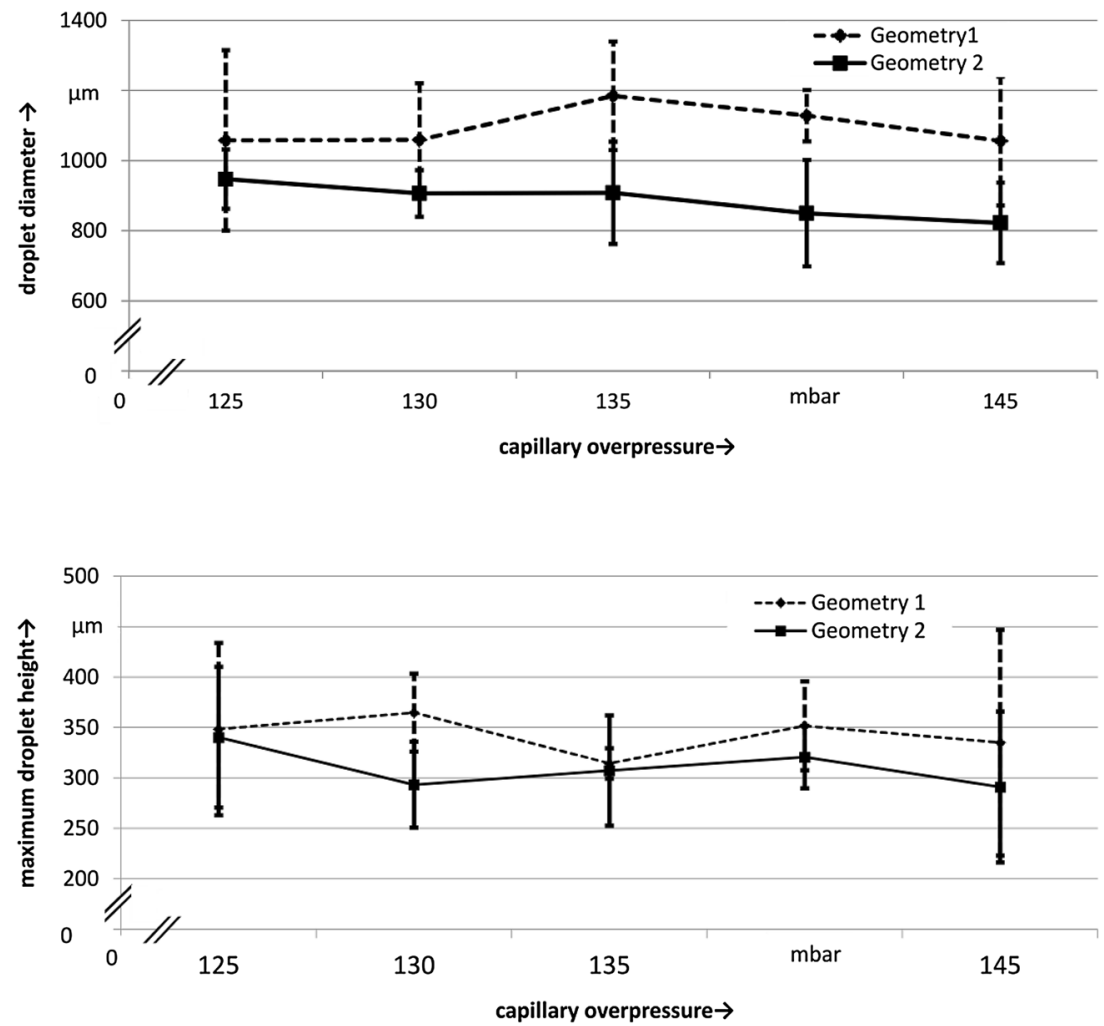
investigated in the scope of this paper. Since a direct measurement of the process dynamics inside the capillary during irradiation and heating of the preform is not possible, a numerical model was set up to describe this crucial process phase. In this context, a numerical FVM model was set up, which takes the surface energies of molten braze (CuSn12) and capillary material $\left(\mathrm{Al}_{2} \mathrm{O}_{3}\right)$ into consideration. The value of the wetting angle was obtained by applying the sessile drop method. Thus, the simulation model considers the wetting behavior of the capillary with molten braze material, Fresnel absorption and intensity distribution of laser radiation as well as heat conductivity and geometry of the capillary as well as the relative overpressure of the machining head to ambient pressure. This approach enabled the evaluation of a spatially resolved time-temperature evolution inside the capillary during a joining cycle. The results indicated heating rates exceeding 22,100 K/s at the orifice of the capillary due to absorbed laser radiation and heat conduction by molten braze material during a joining cycle. A comparison of droplet velocity and melting time shows good accordance of the numerical model and the experiment. Since it is not possible to measure the time temperature evolution inside the capillary directly, the presented numerical approach represents the only method available to obtain space- and time -resolved information regarding heat conduction, convection, and fluid dynamics during one joining cycle. The numerical results indicate that the melting temperature of the used capillary material, $\mathrm{Al}_{2} \mathrm{O}_{3}$ is not exceeded during droplet generation, which is crucial for stable process results in regards of capillary lifetime. In addition geometric deviations of the capillary from the initial shape would result in inhomogeneous process results and thus need to be avoided. During experiments no partial melting of the capillary was observed, which confirms the numeric results.

Further, the influence of capillary geometry on the occurring process gas velocity fields have been evaluated. By modelling a diffuser type capillary instead of a conic shaped one, gas velocities in the joining area could be reduced by $10 \%$ according to the simulation model. To verify the numerical data, both capillary geometries were generated by means of laser ablation from $\mathrm{Al}_{2} \mathrm{O}_{3}$ discs and diameters and heights of solidified droplets generated with both capillaries have been compared. In average, the impact of the capillary shape on the droplet diameter was more significant than on the droplet height. The droplet diameter was reduced by $19.2 \%$ for droplets generated with the diffuser type capillary in comparison with the standard conic capillary shape. In addition, the standard deviation of the droplet diameter could be reduced by $32.2 \%$ by using the diffuser type capillary instead of the conic capillary. Further, the mean droplet height was reduced by $9.5 \%$ and its standard deviation was reduced by $7.5 \%$ by using the modified diffuser type capillary. The results indicate a higher impact of the capillary geometry on the droplet diameter than on the maximum droplet height. Thus the diffuser type capillary is to be favored in future investigations, since it generates more reproducible and uniform droplets than the conic capillary, which was to be expected according to the numerical results. Since the numerical model predicts significant thermal loads during joining, in future works online monitoring of the capillary has to be carried out, in order to determine failure due to the adhesion of braze material or the formation of thermally induced cracks. In addition changing the capillary shape is likely to influence its lifetime, which is also topic of further investigations.

Acknowledgements This research is supported by the Deutsche Forschungsgemeinschaft (DFG) in context of the Collaborative Research Centre/Transregio 39 PT-PIESA, Subproject A04. In addition, the authors gratefully acknowledge cooperation with the Erlangen Graduate School in Advanced Optical Technologies (SAOT) by the Deutsche Forschungsgemeinschaft (DFG) in the framework of the German excellence initiative.

Open Access This article is distributed under the terms of the Creative Commons Attribution 4.0 International License (http:// creativecommons.org/licenses/by/4.0/), which permits unrestricted use, distribution, and reproduction in any medium, provided you give appropriate credit to the original author(s) and the source, provide a link to the Creative Commons license, and indicate if changes were made.

\section{References}

1. Bräutigam V (2008) Gießtechnische Integration piezokeramischer Module in Aluminiumdruckgussbauteile. Dissertation der Technischen Fakultät der Universität Erlangen-Nürnberg, Erlangen

2. Giurgiutiu V (2008) Structural health monitoring with piezoelectric wafer active sensors. Elsevier/Academic Press, Amsterdam, Boston

3. Preumont A (2002) Vibration control of active structures an introduction. Kluwer Academic Publishers, Dordrecht, Boston

4. Aridogan U, Basdogan I (2015) A review of active vibration and noise suppression of plate-like structures with piezoelectric transducers. J Intell Mater Syst Struct 26(12):1455-76

5. Schwankl M, Kimme S, Pohle C, Drossel W-G, Körner C (2015) Active vibration damping in structural aluminum die castings via piezoelectricity - technology and characterization. Adv Eng Mater 17(7):969-975

6. Schwankl M, Flössel M, Köpf J, Körner C, Gebhardt S, Singer RF, Michaelis A (2014) Integration of piezoceramic components in aluminum high pressure die castings. Sensor Actuat A: Phys 207:84-90

7. Stein S, Heberle J, Gürtler FJ, Cvecek K, Roth S, Schmidt M (2014) Influences of nozzle material on laser droplet brazing joints with Cu89Sn11 preforms. In: 8th International conference on laser assisted net shape engineering LANE 2014. Phys Proced 56:709-719 
8. Quentin U, Heberle J, Held C, Schmidt M (2013) Laser droplet brazing for electrical contacting of composite materials with integrated active elements. Proced Mater Sci 2:181-188

9. Stein S, Heberle J, Hugger F, Roth S, Schmidt M (2014) Düsenbasiertes Laserstrahl-Löten mit Formteilen zur hochtemperaturfesten Kontaktierung piezokeramischer Substrate. LEF 2014. In: Laser in der Elektronikproduktion \& Feinwerktechnik Tagungsband: LEF

10. Stein S, Heberle J, Suchy M, Tenner F, Hugger F, Roth S, Schmidt M (2016) High temperature laser based drop on demand micro joining of thin metallic layers or foils using bronze braze preforms. LAMP 2016. JLMN J Laser Micro/Nanoeng 11(1):111-116

11. Jeromen A, Held C, Govekar E, Roth S, Schmidt M (2014) Modelling of droplet detachment in the laser droplet brazing process. J Mater Process Technol 214(4):737-749

12. Dobler M, Schmidt M, Otto A, Leitz K-H (2013) Simulation of process dynamics in laser beam brazing. ICALEO 2013 Paper \#406 (Simulation of Process Dynamics in Laser Beam Brazing). In: Icaleo Conference Proceedings

13. Gürtler FJ, Karg M, Leitz K-H, Schmidt M (2013) Simulation of laser beam melting of steel powders using the three-dimensional volume of fluid method. In: Proceedings of the LIM, Munich

14. Engel TK (1969) The heat capacities of Al2O3, Uo2 and $\mathrm{PuO} 2$ From 300 to $1100^{\circ} \mathrm{K}$. J Nuclear Mater J Nuclear Mater 31(2):211-214

15. Weast RC (1974) CRC handbook of chemistry and physics. A ready-reference book of chemical and physical data, 55th edn. Cleveland

16. Kingery WD, Francl J, Coble RL, Vasilos T (1954) Thermal conductivity: X, Data for several pure oxide materials corrected to zero porosity. J Am Ceram Soc 37:2

17. Anonymous (2004) Kupfer-Zinn-Knetlegierungen (Zinnbronzen). Deutsches Kupferinstitut Auskunfts- und Beratungsstelle für die Verwendung von Kupfer und Kupferlegierungen, Düsseldorf. https://www.kupferinstitut.de/fileadmin/
user_upload/kupferinstitut.de/de/Documents/Shop/Verlag/ Downloads/Werkstoffe/i015.pdf

18. Vitos L, Ruban A, Skriver HL (1998) The surface energy of metals. Surf Sci 411:186-202

19. Brooks R, Egry I, Seetharaman S, Grant D (2001) Reliable data for high-temperature viscosity and surface tension: results from a European project. High Temp High Press 33(6):631-637

20. Zhai W, Wang WL, Geng DL, Wei B (2012) A DSC analysis of thermodynamic properties and solidification characteristics for binary $\mathrm{Cu}-\mathrm{Sn}$ alloys. Acta Mater 60(19):6518-6527

21. Issa RI, Gosman AD, Watkins AP (1986) The computation of compressible and incompressible recirculating flows by a noniterative implicit scheme. YJCPH J Comput Phys 62(1):66-82

22. Hirt CW, Nichols BD (1981) Volume of fluid (VOF) method for the dynamics of free boundaries. YJCPH J Comput Phys 39(1):201-225

23. Lafaurie B, Nardone C, Scardovelli R, Zaleski S, Zanetti G (1994) Modelling merging and fragmentation in multiphase flows with SURFER. J Comput Phys 113(1):134-147

24. Gatzen M, Radel T, Thomy C, Vollertsen F (2014) Wetting behavior of eutectic Al-Si droplets on zinc coated steel substrates. J Mater Process Technol 214(1):123-131

25. Reitz RD, Bracco FV (1982) Mechanism of atomization of a liquid jet. Phys Fluids 25(10):1730-1742

26. Ghassemieh E, Versteeg HK, Acar M (2006) The effect of nozzle geometry on the flow characteristics of small water jets. Proc Inst Mech Eng Part C J Mech Eng Sci 220:1739-1753. doi:10.1243/0 954406JMES430

27. Häfner T, Hofmann L, Eiselen S (2013) Einsatz der Simulation zur Optimierung der Abtragsrate beim Strukturieren mittels Pikosekundenlaser. In: Tagungsband Laser in der Elektronikproduktion und Feinwerktechnik, pp 51-55

28. Dobrovinskaya ER, Litvinov LA, Pishchik V (2009) Sapphire: Material, manufacturing, applications. Springer. doi:10.1007/978-0-387-85695-7 